\title{
Intravascular Virtual MR Endoscopy Evaluation of Cerebral Aneurysms
}

\author{
Serebral Anevrizmaların Değerlendirilmesinde Intravasküler Sanal MR \\ Endoskopi
}

Lutfi INCESU ${ }^{1}$, Kerim ASLAN ${ }^{1}$, Ahmet Veysel POLAT ${ }^{1}$, Cengiz COKLUK ${ }^{2}$, Zuhal Candan ERENLER ${ }^{3}$, Onur TOKATLIOGLU ${ }^{4}$, Mehmet Ozgur YILDIRIM 5 , Haldun Baris DIREN ${ }^{6}$

${ }^{1}$ Ondokuz Mayis University, Faculty of Medicine, Department of Radiology, Samsun, Turkey

${ }^{2}$ Ondokuz Mayis University, Faculty of Medicine, Department of Neurosurgery, Samsun, Turkey

${ }^{3}$ Giresun State Hospital, Department of Radiology, Giresun, Turkey

${ }^{4}$ Samsun Buyuk Anadolu Hospital, Department of Radiology, Samsun, Turkey

${ }^{5}$ Mediva Hospital, Department of Radiology, Samsun, Turkey

${ }^{6}$ Medicana International Ankara Hospital, Department of Radiology, Ankara, Turkey

Corresponding Author: Kerim ASLAN / E-mail: mdkerim@hotmail.com

\begin{abstract}
AIM: The aim of this study was to evaluate the role of intravascular virtual MR endoscopy in the planning of correct surgical clipping of the aneurysm neck.

MATERIAL and METHODS: A total of 36 aneurysms were detected by using magnetic resonance angiography (MRA) in thirty patients. Intravascular virtual MR endoscopy is a realistic 3-dimensional simulation of intravascular structures that is generated by postprocessing of MRA maximum-intensity projection images. The images were evaluated by two neuroradiologists, in terms of image quality via qualitative analysis of MRA and intravascular virtual MR endoscopy of the orifice of the aneurysm neck, as well as the relationship of the main and bifurcating arteries with the orifice of the aneurysm. The readers were fully blinded. Mann-Whitney $U$ test was used to compare the differences in mean scores for each reader between these two groups.

RESULTS: Based on the scoring system, evaluating image quality using qualitative analysis, both readers found the mean scores to be $3.82 \pm$ 0.52 and $3.91 \pm 0.72$ for intravascular virtual MR endoscopy, and $2.97 \pm 0.71$ and $2.89 \pm 0.83$ for MRA, which was statistically different ( $p<0.001$ ). CONCLUSION: Intravascular virtual MR endoscopy may provide useful knowledge in the proper the surgical clipping of the aneurysm neck. KEYWORDS: Cerebral aneurysm, Intravascular virtual MR endoscopy, Magnetic resonance angiography
\end{abstract}

öz

AMAÇ: Bu çalışmanın amacı, anevrizma boynunun doğru cerrahi kliplenmesinin planlanmasında intravasküler sanal MR endoskopinin rolünü değerlendirmektir.

YÖNTEM ve GEREÇLER: 30 hastada 36 anevrizma magnetik rezonans anjiyografi (MRA) kullanılarak ortaya çıkarıldı. İntravasküler sanal MR endoskopi, MRA maximum-intensity projeksiyon görüntülemenin işlenmesinden üretilen intravasküler yapıların gerçekçi 3 boyutlu simülasyonudur. İki nöroradyolog tarafından MRA ve intravasküler sanal MR endoskopide anevrizma boynunun orifisi ve anevrizmanın orifisi ile bifurkasyon arter ve ana arterin ilişkisi kalitatif analiz vasıtasıyla görüntü kalitesi açısından değerlendirildi. İki okuyucu tamamen bağımsızdı. Bu iki grup arasındaki her bir okuyucu için ortalama puan farkının anlamlıığına Mann-Whitney testi ile karşılaştırıldı.

BULGULAR: Kalitatif analiz kullanılarak görüntü kalitesini puanlama sistemine göre değerlendirilmesinde her iki okuyucu intravasküler sanal MR endoskopi için $3.82 \pm 0.52$ ve $3.91 \pm 0.72$; MRA için $2.97 \pm 0.71$ ve $2.89 \pm 0.83$ ortalama skora sahipti ve bu fark istatistiksel olarak anlamlıydı $(\mathrm{p}<0.001)$.

SONUÇ: Intravasküler sanal MR endoskopi anevrizma boynunun uygun cerrahi kliplenmesinde faydalı bilgi sağlayabilir.

ANAHTAR SÖZCÜKLER: Serebral anevrizma, İntravasküler sanal MR endoskopi, Magnetik rezonans anjiyografi

\section{INTRODUCTION}

Cerebral aneurysms are found in $1 \%$ to $14 \%$ of the population. Intracranial aneurysms represent the most common atraumatic cause of subarachnoid hemorrhage (SAH). Unruptured aneurysms are most often asymptomatic (17).
Aneurysms can be classified based on a number of features, including morphology (e.g., saccular, fusiform), size, location (e.g., intradural, extradural), and etiology (e.g., congenital, traumatic, neoplastic, dissecting, mycotic, atherosclerotic). Most intracranial aneurysms are saccular aneurysms (22). 
Magnetic resonance angiography (MRA) is a non-invasive imaging technique based on the detection of blood flow within the cerebral vessels. Its primary advantage is that it provides us with very thin sections, which produce almost sub-mm source images that can be viewed later using both two-dimensional (2D) and three-dimensional (3D) modes. The main disadvantages of this technique are the prolonged acquisition time and artifacts due to flow phenomena and patient motion (14). Over the past decade, technical developments in MR imaging have made it possible to produce an endoluminal view of hollow organs. These techniques have yielded images that are similar to those obtained via endoscopy. These imaging protocols allow patients to undergo a "virtual endoscopy" (27). Virtual MR endoscopic techniques are used to gain an image display using computer processing of $3 \mathrm{D}$ data sets to provide a simulated visualization of a patient's hollow organs similar to that produced by standard endoscopes $(16,23,27)$.

Studies have described clinical applications of virtual endoscopy to visualize the inside of the bronchi, paranasal sinus, stomach, bladder, small intestine, pancreatic duct, bile duct, and spine $(2,6,8,10,11,16,19,21,23,24)$. Shigematsu et al. (20) reported the use of virtual intravascular MR endoscopy for aneurysms in three cases. Colpan et al. (5) evaluated the effectiveness of using virtual CT endoscopy during intracranial aneurysm surgery. To our knowledge, there is no large series in the English-language literature related to the cerebral aneurysm perspective via evaluating intravascular virtual MR endoscopy.

The evaluation of the internal morphology of main arteries with saccular aneurysms and the orifice of the aneurysm neck, the origin of the bifurcating artery, and the relationship of the main and bifurcating arteries to the orifice of the aneurysm neck is important in the planning of correct surgical clipping of the aneurysm neck. The aim of this study was to evaluate the role of intravascular virtual MR endoscopy in the planning of correct surgical clipping of the aneurysm neck.

\section{MATERIAL and METHODS}

By using our institute's database from April 2007 to February 2008 , we found patients who presented with severe headache and were found to have subarachnoid hemorrhage (SAH) on non-enhanced computed tomography and had undergone multidetector computed tomography angiography (MDCTA) and MRA to include in the study. Thirty patients (age range 1275 years; mean age $52.29 \pm 3.49), 12(40 \%)$ male and $18(60 \%)$ female, were included in this study. Thirty-six aneurysms were detected in 30 patients by MDCTA and MRA. Our study was approved by our institutional ethics committee.

\section{Imaging}

All patients underwent $\mathrm{CT}$ study with an Aquilion scanner (Toshiba Medical Systems, Tokyo, Japan) with 16-row MDCTA. The CT parameters used included section thickness $(1 \mathrm{~mm})$, field of view $(25 \mathrm{~cm}), \mathrm{kV}(120), \mathrm{mA}(300)$, and pitch (1.5). The patient received $2 \mathrm{~mL} / \mathrm{kg}$ nonionic contrast medium
$(370 / 110 \mathrm{mg} / \mathrm{mL})$ via an indwelling 24-gauge antecubital catheter with automated intravenous contrast injector. The contrast agent was given with a 25 -sec delay at a speed of $4 \mathrm{~mL} / \mathrm{sec}$. 3D images were reconstructed using maximum intensity projection (MIP) and 3D rendering algorithms on a Vitrea 2 (vital image) workstation. The $0.5-\mathrm{mm}$-thick axial source images were reconstructed to 1-mm-thick sagittal and coronal images with $50 \%$ reconstruction overlap. All patients were scanned using a 1.5T scanner (Siemens Magnetom Symphony Quantum, Erlangen, Germany). Data recorded included 3D time-of-flight (3D TOF) MRA protocol, echo time (19 $\mathrm{ms})$, repetition time $(5.7 \mathrm{~ms})$, flip angle $\left(16^{\circ}\right)$, the number of signal averages (2), field of view $(18 \mathrm{~cm})$, slice thickness (1 $\mathrm{mm})$, and matrix dimensions $(230 \times 256)$.

3D TOF MRA data were transferred to a workstation (Leonardo, Siemens) computer system. Intravascular virtual MR endoscope techniques were used on MRA MIP images. To obtain an intracranial view, we manually determined the central point of the vessels in the axial, sagittal, and coronal planes, from which we generated virtual endoscopic images. The virtual endoscopy software then allowed us to explore the vessels with a mouse and manually draw a path as we navigated through various multiplanar reformations. The selected images were then automatically reconstructed along this predetermined path to create "fly-through" movies sequentially moving cranially to caudally along this flight path to simulate the continual progression of an endoscope down the vessels. Images in three planes helped the operator orient to the anatomy depicted on the 3D display and steer the virtual endoscope view via fly-through. A threshold value (low 0, high 200) was selected for surface-shaded displays. Using the fly-through technique, we evaluated the presence of aneurysms, the inner surface textures of aneurysms, and the orifice of the aneurysm neck by moving inside vessels related to aneurysms.

We performed the virtual endoscopic examination of intracranial aneurysms by applying navigator-perspective endoscopic algorithm MRA MIP images. By moving the observation point applied to the brain vessels in the study area at a specific angle, we could obtain precise information about the presence of aneurysms in very small vessels, such as communicant arteries, size, neck of aneurysm, internal aneurysm structure, and defects in the walls with a risk of perforation of the aneurysm.

The images were evaluated by two neuroradiologists in terms of image quality via qualitative analysis of 3D TOF MRA and intravascular virtual MR endoscopy images of the orifice of the aneurysm neck, the origin of the bifurcating artery, and the relationship of the main and bifurcating arteries to the orifice of the aneurysm. The readers were fully blinded. Image quality was assessed using a subjective five-point scale; 5 was excellent, 4 was good, 3 was medium, 2 was weak, and 1 was very weak. In terms of image quality, the mean score was calculated separately for each reader according to a subjective scoring of 3DTOF MRA and intravascular MR virtual 
endoscopy images via qualitative analysis. The mean scores were calculated for both readers for intravascular virtual MR endoscopy and MRA. The difference in mean scores for each readers was compared by the Mann-Whitney $U$ test. We used SPSS version 15.0; $p<0.05$ was accepted as statistically significant.

\section{RESULTS}

The anterior communicating artery ( $A C O A)$ was the most common location of aneurysms in our series. Of the 36 aneurysms, 11 (30\%) were in the ACoA, 8 (22\%) were in the middle cerebral artery (MCA) and bifurcations, 6 (17\%) were in the posterior communicating artery (PCoA), 1 (3\%) was in the anterior cerebral artery (ACA), 2 (5.5\%) were in the posterior cerebral artery (PCA), 4 (11\%) were in the ICA and segments, $2(5.5 \%)$ were in the posterior inferior cerebellar artery (PICA), $1(3 \%)$ was in the ophthalmic artery, and 1 (3\%) was in the basilar artery. The locations of the aneurysms in our study group are summarized in Table I. Of the 36 aneurysms, 3 (8\%) were fusiform, 2 (5.5\%) were located at the PCA, 1 was located at the PCoA, and the rest were saccular. The diameter of two (5.5\%) of the aneurysms were $75 \mathrm{~mm}$ and $25 \mathrm{~mm}$ (giant aneurysms), while the largest of the other aneurysms was $11.7 \mathrm{~mm}$; the smallest was $1.7 \mathrm{~mm}$. No statistically significant differences in MDCTA and MRA were found in terms of number of aneurysms, localization, and neck of aneurysm. The sizes of the aneurysms that were detected by MDCTA/ MRA are summarized in Table II.

Based on the scoring system for evaluating image quality using qualitative analysis, both readers found the mean scores to be $3.82 \pm 0.52$ and $3.91 \pm 0.72$ for virtual MR endoscopy, and 2.97 \pm 0.71 and $2.89 \pm 0.83$ for MRA (Table III). The highest mean score belonged to the intravascular virtual MR endoscopy for both readers. The mean score difference between 3D TOF MRA and virtual intravascular MR endoscopy was statically significant $(p<0.001)$ for both readers.

The orifice of the PCoA in six cases, the relationship to the ICA (Figure 1), and the leaving-branch $\mathrm{PCOA}$ were demonstrated by the virtual MR endoscope technique (Figures $2 A-C, 3 A-D$, $4 A-D)$. The location of the orifice of the ACoA aneurysm in the ACoA and the leaving-branch ( 22 segment of the ACA) were also demonstrated with this technique (Figure $5 A-C$ ). In cases of MCA aneurysms, the orifice of the bifurcating artery and its relationship to the M2 branches (Figure 4A-D) were demonstrated. We showed in 10 cases the presence of thrombus in the aneurysm via virtual intravascular MR endoscopy (Figure 1A-C).

\section{DISCUSSION}

Demonstrating a detailed internal anatomy of an aneurysm and its leaving-branches may help with the proper surgical repairing and clipping of the aneurysm neck. It is sometimes difficult to evaluate the neck and the internal structure of an aneurysm by MDCTA and MRA. The relationship of the main and bifurcating arteries to the orifice of the aneurysm neck is difficult to comprehend by traditional rendering techniques
Table I: The Localization of Intracranial Aneurysms

\begin{tabular}{|c|c|}
\hline Localization & Number of aneurysms (\%) \\
\hline ACoA & $11(30 \%)$ \\
\hline MCA & $8(22 \%)$ \\
\hline PCoA & $6(17 \%)$ \\
\hline ICA & $4(11 \%)$ \\
\hline PCA & $2(5.5 \%)$ \\
\hline PCA & $2(5.5 \%)$ \\
\hline OCA & $1(3 \%)$ \\
\hline BA & $1(3 \%)$ \\
\hline Total & $1(3 \%)$ \\
\hline
\end{tabular}

ACA, anterior cerebral artery; $\mathbf{A C O A}$, anterior communicating artery; BA, basilar artery; ICA, internal carotid artery; $\mathbf{M C A}$, middle cerebral artery; OA, ophthalmic artery; PCA, posterior cerebral artery; PCoA, posterior communicating artery; PICA, posterior inferior cerebellar artery

Table II: The Size of Intracranial Aneurysms

\begin{tabular}{|c|c|}
\hline $\begin{array}{c}\text { Maximum aneurysm } \\
\text { diameter }(\mathrm{mm})\end{array}$ & Number of aneurysms (\%) \\
$<3$ & $3(8 \%)$ \\
$3-10$ & $28(78 \%)$ \\
$>10$ & $5(14 \%)$ \\
\hline
\end{tabular}

Table III: Qualitative Assessment of Image Quality

\begin{tabular}{|l|c|c|}
\hline & \multicolumn{2}{c|}{ Image Quality } \\
\hline & Reader 1 & Reader 2 \\
\hline MRA & $2.97 \pm 0.71$ & $2.89 \pm 0.83$ \\
\hline $\begin{array}{l}\text { Intravascular virtual MR } \\
\text { endoscope }\end{array}$ & $3.82 \pm 0.52$ & $3.91 \pm 0.72$ \\
\hline
\end{tabular}

MRA, magnetic resonance angiography.

that require surgeons to mentally envisage the tubular views from sequential $2 \mathrm{D}$ cross-sectional data, a procedure that requires much experience.

Volume rendering allows the production of images of the inner surface of the tubular lumens; this technique has been named virtual endoscopy. Virtual endoscopy is a new way to describe an image display method using computer processing of $3 D$ data sets to provide a simulated visualization of a patient's hollow organs similar to that produced by standard endoscopy. It provides a realistic 3D intraluminal simulation of cavities that is generated by processing volumetric data sets using specialized software packages and powerful workstations $(1,9,11,13,27)$.

This rendering technique is one of the most important technical determinants of virtual endoscopy. The two methods widely in use are perspective rendering and orthographic external rendering with cut planes. Orthographic rendering 


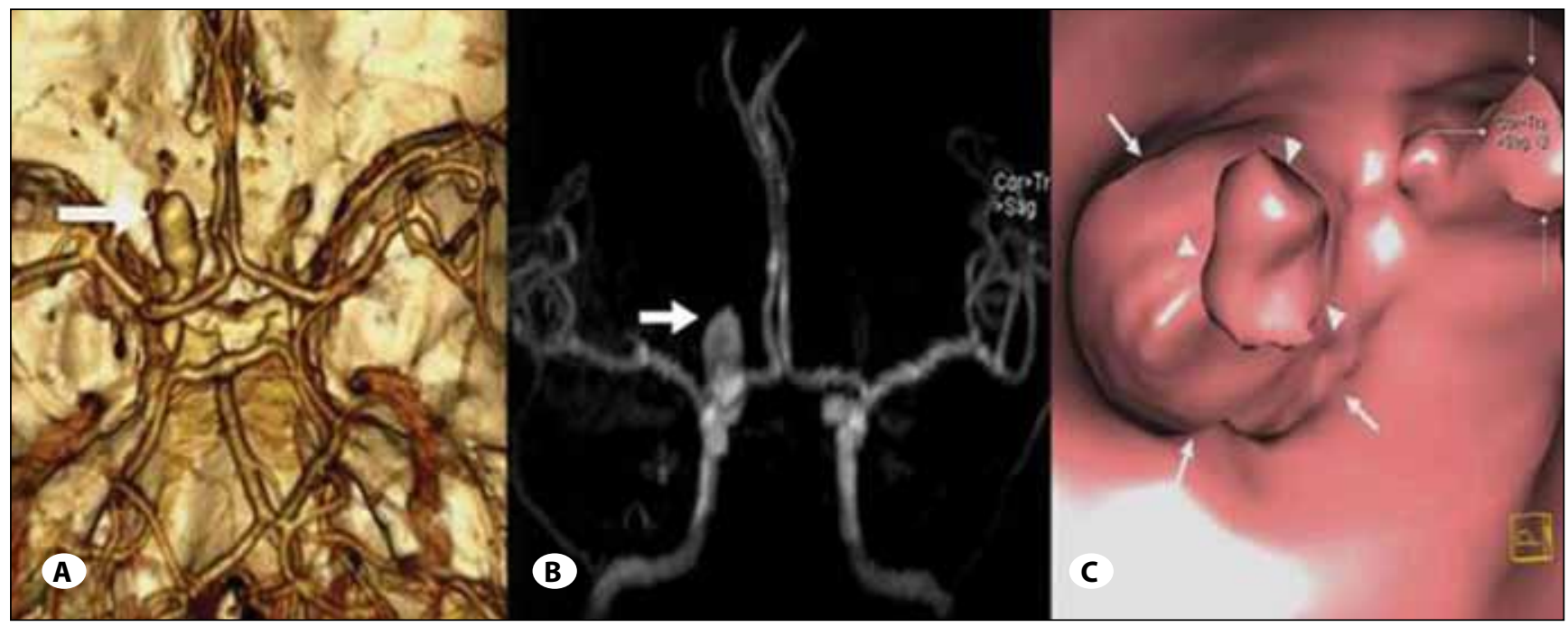

Figure 1: A) MDCTA and B) MIP MRA images showing saccular aneurysm at the right ophthalmic artery. C) Intravascular virtual MR endoscopic image of the same patient showing the lumen of the ICA supraclinoid segment (thin arrows), aneurysmal sac (thick arrow) and thrombus (arrowhead).

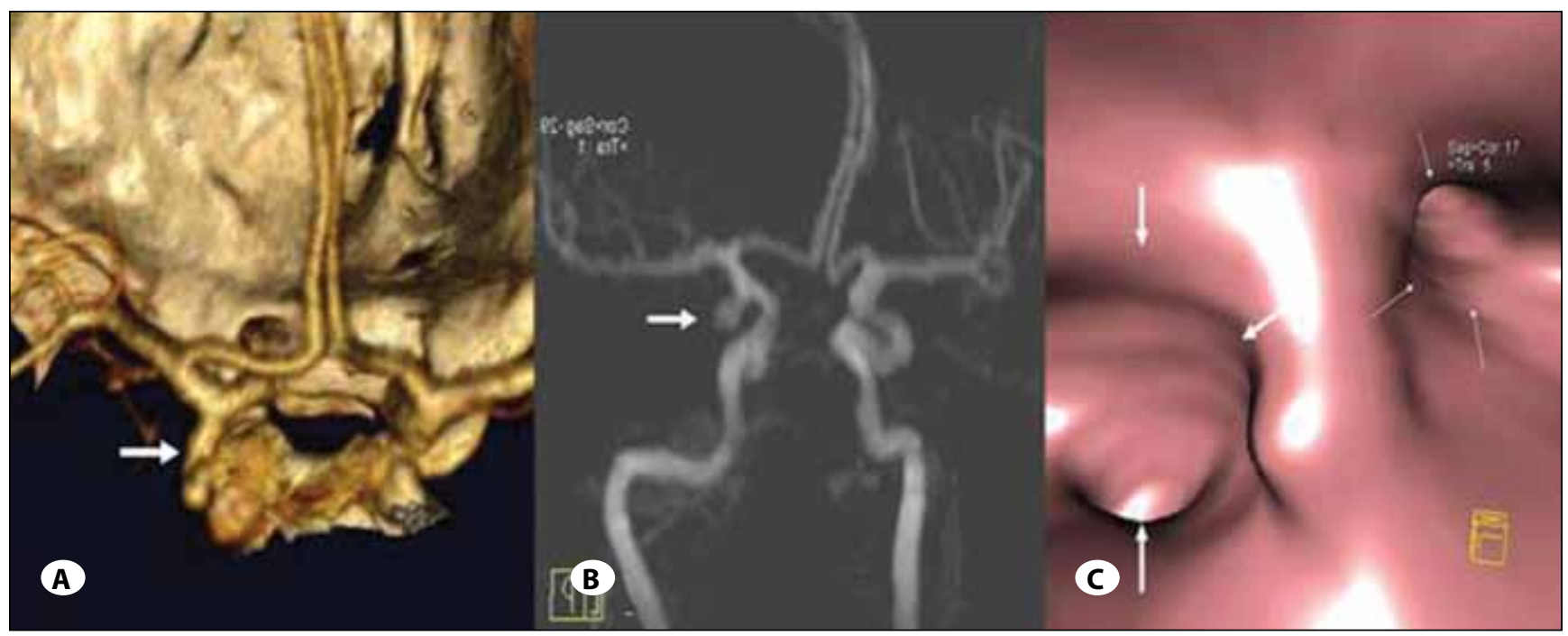

Figure 2: A) MDCTA and B) MIP MRA images showing saccular aneurysm at the right PCoA (arrow). C) The aneurysmal sac (thick arrows) is seen in the intravascular virtual MR endoscopic image of the same patient, acquired by entering the PCoA (thin arrows).

is the most commonly used technique, particularly for the external visualization of a lumen from a viewpoint external to the data. However, it can also be used for internal visualization when combined with cut planes positioned within the lumen of the structure of interest. This method cannot provide a continuous demonstration of all interior surfaces of a lumen. In perspective rendering, the viewpoint using is from within the lumen, mimicking fiber-optic endoscopy and bypassing the limitations of the invasive technique that requires access to the lumen and has a restricted visual direction $(1,18)$. Recently, a perspective volume rendering method was applied with a virtual endoscopic algorithm. With this method, the volume data are rendered from a point source at a finite distance to approximate the human visual system.
Although virtual endoscopy does not allow direct physical biopsy or treatment options, an established technique will be useful for preoperative simulation and the 3D perception of lesions $(6,20)$.

Studies have described clinical applications of virtual endoscopy to visualize the inside of the tracheobronchial tree, paranasal sinus, stomach, bladder, small intestine, pancreatic duct, bile duct, and spine $(2,6-8,10,11,16,19,21,23,24)$. Virtual endoscopy used for preoperative planning in neurosurgery for endoscopic third ventriculostomy, nasal cavity and paranasal sinus surgery, and virtual endoscopy visualization of the sphenoid sinus and important adjacent structures is valuable for training and the preoperative planning of endonasal transsphenoidal surgery (15). Virtual endoscopy 

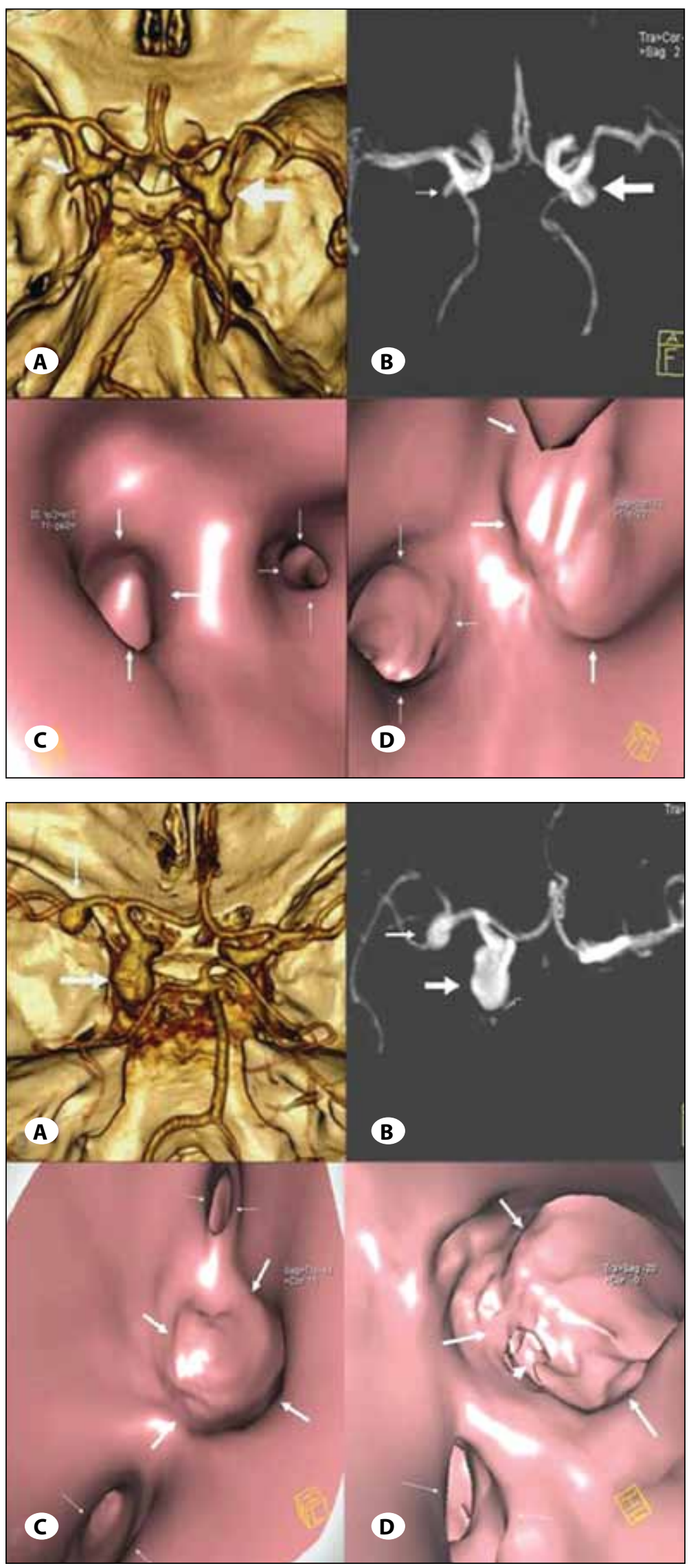

Figure 3: A) MDCTA and B) MIP MRA images showing bilateral saccular aneurysms at the PCoA. Moving inside $\mathbf{C}$ ) the right and $\mathbf{D}$ ) left PCoA (thin arrows) by intravascular virtual MR endoscopy allowed us to see the shape, and internal surface texture (thick arrows) of the aneurysmal sacs.
Figure 4: A) MDCTA and B) MIP MRA images showing saccular aneurysms at the right PCoA (thick arrow), and the right MCA bifurcation (thin arrow). Intravascular virtual MR endoscopic image acquired by entering the $C$ ) $M 2$ segment of the right MCA (thin arrows) and D) PCoA (thin arrows) aneurysmal sacs (thick arrows) are shown. 


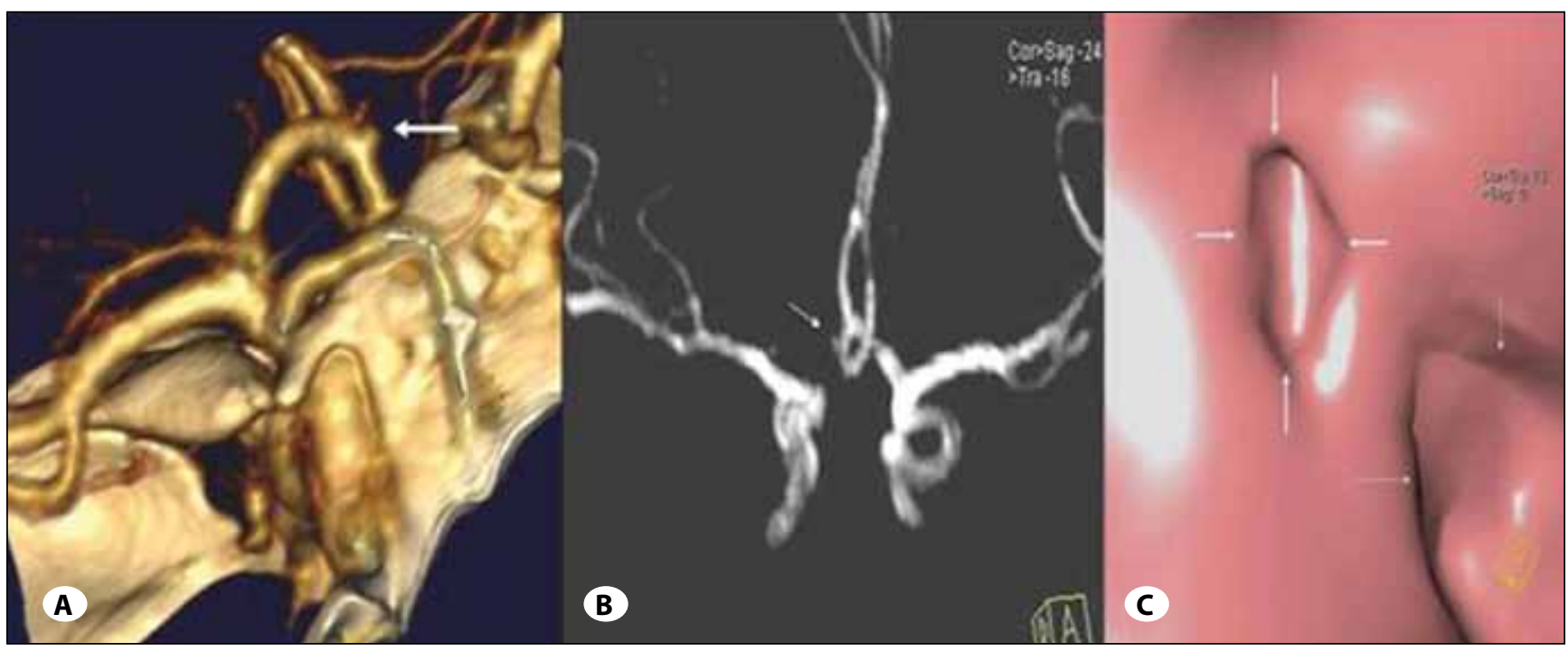

Figure 5: A) MDCTA and B) MIP MRA images, of a saccular aneurysm at the ACoA (arrow). C) An intravascular virtual MR endoscopic image of the same patient shows the left ACA A2 segment (thin arrow) and an adjacent aneurysmal sac (thick arrow).

was used to evaluate intracranial aneurysms. Colpan et al. (5) examined the use of CTA images employed with virtual endoscopy image processing techniques to better assess intracranial vasculature during aneurysm surgery and to evaluate its effect on surgical outcomes, and reported significantly reduced complication rates in aneurysm surgery as a result of virtual endoscopy. Tanoue et al. (25) evaluated the accuracy of rotational digital subtraction angiography in $3 D$ reconstructed images of intracranial aneurysm surgeries; they showed the efficacy of 3D digital subtraction angiography guides for surgeons in terms of understanding the $3 \mathrm{D}$ views of structures, and help with the preoperative surgical planning of cerebral aneurysms.

Intravascular virtual MR endoscope is a non-invasive and non-ionizing radiation imaging technique in comparison virtual digital substraction angiographic endoscopy. The invasive nature of virtual digital substraction angiographic endoscopy is an additional disadvantage, carrying a $0.4-0.5 \%$ rate of persistent neurological complications, and a low but significant $1 \%$ complication risk related to arterial puncture and catheter manipulation $(26,12)$. The intravascular virtual MR endoscope therefore has extremely rare complications related with technique. Virtual CT endoscopy presents some difficulties in evaluating aneurysms located near bone structures and includes ionizing radiation (12).

MR endoscopy was routinely used for the large abdominal and thoracic vessels; however, studies regarding its use in intracranial applications are limited. The use of intravascular virtual MR endoscopy for the evaluation of intracranial aneurysms is quite rare. In a different study, Bontozoglou et al. $(3,4)$ described the size of the aneurysmal sac and its orifice using 3D endovascular MR angiography via an orthographic rendering method. As far as we know, only Shigematsu et al. (20) described the use of intravascular virtual MR endoscopy with a perspective-rendering method for intracranial aneurysm in the English-language literature; they showed that it is helpful when coupled with MRI, and they suggest that additional clinical trials be held for demonstrating its efficacy. In our study, as Shigematsu et al. (20) have done, we evaluated intravascular virtual MR endoscopy of the orifice of the aneurysm neck, as well as the relationship of the main and bifurcating arteries to the orifice of the aneurysm, using the perspective method.

Aneurysmatic dilatations of the vessels generally originate from the bifurcation of the basal cerebral arteries. In the clipping of the aneurysm neck, knowledge about the relationship between the aneurysm neck and its main trunk and perforating arteries is extremely important for the proper clipping of the neck. In this clinical study, we investigated the internal structure of the aneurysm by using intravascular virtual MR endoscopy, and we examined the relationship of the $A C o A$, aneurysm orifice, and $A 2$ orifice to the aneurysm neck and the relationship of the PCoA and the ICA aneurysm originating near the posterior communicating bifurcation. Our study also showed the relationship of the aneurysm to the MCA bifurcation, as well as the origin of the M2 segments. We clearly revealed the presence of thrombus in aneurysms via virtual intravascular MR endoscopy. While none of the thrombi in aneurysms was shown by MRA in our cases, we were able to show thrombus by CTA in one case. We showed in 10 cases the presence of thrombus in the aneurysm via virtual intravascular MR endoscopy. Knowledge about the internal structures of MCA bifurcation aneurysms is important for proper clipping of the aneurysm neck.

In our study, when compared with 3D TOF MRA in terms of evaluating the orifice of the aneurysm neck, intravascular virtual MR endoscopy was found to be more advantageous for surgeons in demonstrating the origin of the bifurcating 
artery, as well as the relationship of the main and bifurcating arteries to the orifice of the aneurysm neck. This study is a pioneer study in terms of evaluating aneurysms via intravascular virtual MR endoscopy with qualitative analysis, and is proposed as a guide for future studies on this subject. However, the limitations of the study were the absence of a comparison of the qualitative analysis results with surgery reports. Nevertheless, the origin of the bifurcating artery, as well as the relationship of the main and bifurcating arteries to the orifice of the aneurysm neck, were demonstrated in detail, and it is proposed that this method may be useful for the planning of correct surgical clipping of the aneurysm neck.

\section{CONCLUSIONS}

With its limitations, the intravascular virtual MR endoscope technique was used to demonstrate the internal morphological structure of the basal cerebral arteries, the orifice of the aneurysm neck, the origin of the bifurcating artery, and the relationship of the main and bifurcating arteries to the orifice of the aneurysm neck. The intravascular virtual MR endoscope technique may provide detailed information about the internal morphology of the main artery and the origin of the aneurysm neck. It may also be helpful in the proper surgical clipping of the aneurysm neck.

\section{REFERENCES}

1. Andronikou S, Irving B, Hlabangana LT, Pillay T, Taylor P, Goussard P, Gie R: Technical developments in postprocessing of paediatric airway imaging. Pediatr Radiol 43:269-284, 2013

2. Azuma T, Yamaguchi $K$, lida T, Oouhida J, Suzuki M: MR virtual endoscopy for biliary tract and pancreatic duct. Magn Reson Med Sci 6:249-257, 2007

3. Bontozoglou N, Spanos H, Lasjaunias P, Zarifis G: Intracranial aneurysms: Endovascular evaluation with three-dimensionaldisplay MR angiography radiology 197:876-879, 1995

4. Bontozoglou N, Spanos H, Lasjaunias P, Zarifis G: Three-dimensional display of the orifice of intracranial aneurysms: $A$ new potential application of magnetic resonance angiography. Neuroradiology 36:346-349, 1994

5. Colpan ME, Sekerci Z, Cakmakci E, Donmez T, Oral N, Mogul DJ: Virtual endoscope assisted intracranial aneurysm surgery: Evaluation of fifty-eight surgical cases. Minim Invasive Neurosurg 50:27-32, 2007

6. Dearking AC, Pallanch JF: Mapping the frontal sinus ostia using virtual endoscopy. Laryngoscope 122:2143-2147, 2012

7. Fenlon HM, Bell TV, Ahari HK, Hussain S: Virtual cystoscopy: Early clinical experience. Radiology 205:272-275, 1997

8. Furukawa K, Miyahara R, Itoh A, Ohmiya N, Hirooka Y, Mori $\mathrm{K}$, Goto H: Diagnosis of the invasion depth of gastric cancer using MDCT with virtual gastroscopy: Comparison with staging with endoscopic ultrasound. AJR Am J Roentgenol 197:867-875, 2011

9. Higgins WE, Ramaswamy K, Swift RD, McLennan G, Hoffman EA: Virtual bronchoscopy for three dimensional pulmonary image assessment: State of the art and future needs. Radiographics 18:761-778, 1998

10. Kiraly AP, Higgins WE, McLennan G, Hoffman EA, Reinhardt JM: Three-dimensional human airway segmentation methods for clinical virtual bronchoscopy. Acad Radiol 9:1153-1168,2002
11. Kotani T, Nagaya S, Sonoda M, Akazawa T, Lumawig JM, Nemoto T, Koshi T, Kamiya K, Hirosawa N, Minami S: Virtual endoscopic imaging of the spine. Spine 37:752-756, 2012

12. Kouskouras C, Charitanti A, Giavroglou C, Foroglou N, Selviaridis $\mathrm{P}$, Kontopoulos V, Dimitriadis AS: Intracranial aneurysms: Evaluation using CTA and MRA. Correlation with DSA and intraoperative findings. Neuroradiology 46: 842-850, 2004

13. Krombach GA, Rohde V, Haage $P$, Struffert T, Kilbinger $M$, Thron A: Virtual endoscopy combined with intraoperative neuro navigation for planning of endoscopic surgery in patients with occlusive hydrocephalus and intracranial cysts. Neuroradiology 44: 279-285, 2002

14. Malamateniou C, Adams ME, Srinivasan L, Allsop JM, Counsell SJ, Cowan FM, Hajnal JV, Rutherford MA: The anatomic variations of the circle of willis in preterm-at-term and termborn infants: An MR angiography study at 3T. AJNR Am J Neuroradiol 30:1955-1962, 2009

15. Neubauer A, Wolfsberger S: Virtual endoscopy in neurosurgery: A review. Neurosurgery 72:97-106, 2013

16. Qu X, Huang X, Wu L, Huang G, Ping X, Yan W: Comparison of virtual cystoscopy and ultrasonography for bladder cancer detection: A meta-analysis. Eur J Radiol 80:188-197, 2011

17. Rosenorn J, Eskesen V, Schmidt K: Unruptured intracranial aneurysms: An assessment of the annual risk of rupture based on epidemiological and clinical data. Br J Neurosurg 2:369-377, 1988

18. Rubin GD: 3-D imaging with MDCT. Eur J Radiol 45:37-41, 2003

19. Schreyer AG, Herfarth H, Kikinis R, Seitz J, Schölmerich J, Geissler A, Feuerbach S: 3D modeling and virtual endoscopy of the small bowel based on magnetic resonance imaging in patients with inflammatory bowel disease. Invest Radiol 37:528-533, 2002

20. Shigematsu $Y$, Korogi $Y$, Hirai T, Okuda T, Sugahara T, Liang L, Ge Y, Takahashi M: Virtual MR endoscopy of the central nervous system. J Magn Reson Imaging 8:289-296, 1998

21. Sodhi KS, Aiyappan SK, Saxena AK, Singh M, Rao K, Khandelwal $\mathrm{N}$ : Utility of multidetector CT and virtual bronchoscopy in tracheobronchial obstruction in children. Acta Paediatr 99:1011-1015, 2010

22. Stoodley MA, Macdonald RL, Weir BK: Pregnancy and intracranial aneurysms. Neurosurg Clin N Am 9:549-556, 1998

23. Suleyman E, Yekeler E, Dursun M, Zorba UO, Tunc M, Tunaci A, Acunas B: Bladder tumors: virtual MR cystoscopy. Abdom Imaging 31:483-489,2006

24. Taimouri V, Liu X, Lai Z, Liu C, Pai D, Hua J: Colon segmentation for prepless virtual colonoscopy. IEEE Trans Inf Technol Biomed 15:709-715, 2011

25. Tanoue $\mathrm{S}$, Kiyosue $\mathrm{H}$, Kenai $\mathrm{H}$, Nakamura T, Yamashita M, Mori $\mathrm{H}$ : Three-dimensional reconstructed images after rotational angiography in the evaluation of intracranial aneurysms: Surgical correlation. Neurosurgery 47:866-871, 2000

26. Villablanca JP, Jahan R, Hooshi P, Lim S, Duckwiler G, Patel A, Sayre J, Martin N, Frazee J, Bentson J, Viñuela F: Detection and characterization of very small cerebral aneurysms by using 2D and 3D helical CT angiography. AJNR Am J Neuroradiol 23:1187-1198, 2002

27. Vining DJ, Zagoria RJ, Liu K, Stelts D: CT cystoscopy: An innovation in bladder imaging. AJR 166:409-410, 1996 